\title{
Distribution and conservation of the transposable element gypsy in Drosophilid species
}

\author{
Fabiana Herédia $^{1}$, Elgion Lúcio S. Loreto ${ }^{2}$ and Vera Lúcia S. Valente ${ }^{1}$ \\ ${ }^{1}$ Departamento de Genética, Instituto de Biociências, Universidade Federal do Rio Grande do Sul, \\ Porto Alegre, RS, Brazil. \\ ${ }^{2}$ Departamento de Biologia, Instituto de Ciências Exatas e Naturalism, Universidade Federal de Santa \\ Maria, Santa Maria, RS, Brazil.
}

\begin{abstract}
In an attempt to understand the dynamics of transposable elements (T'S) in the genome of host species, we investigated the distribution, representativeness and conservation of DNA sequences homologous to the Drosophila melanogaster gypsy retrotransposon in 42 drosophilid species. Our results extended the knowledge about the wide distribution of gypsy in the genus Drosophila, including several Neotropical species not previously studied. The gypsy-like sequences showed high divergence compared to the $D$. melanogaster gypsy element. Furthermore, the conservation of the restriction sites between gypsy sequences from phylogenetically unrelated species pointed to a more complex evolutionary picture, which includes the possibility of the horizontal transfer events already described for this retrotransposon.
\end{abstract}

Key words: Drosophila, retrotransposon, gypsy, Southern blot, PCR.

Received: December 16, 2005; Accepted: August 1, 2006.

The superfamily of retrotransposons Ty3/gypsy is widely distributed among living organisms (Miller et al., 1999; Marin \& Lloréns 2000), and its relationship with retroviruses has been inferred in several studies (Xiong and Eickbush 1990; Kim et al., 1994; Pelisson et al., 1997 and Lerat \& Capy 1999).

The gypsy retroelement (also known as $m d g 4$ ) was first described in Drosophila melanogaster as a $7.5 \mathrm{~kb}$ sequence with 482 bp-long terminal repeats (LTRs) (Georgiev et al., 1981; Bayev et al., 1984). Kim et al. (1994) published evidence that culminated in the characterization of gypsy as the first retrovirus in invertebrates. As in other retroviruses, the gypsy retrotransposon has three open reading frames (ORFs) called gag, pol and env, encoding proteins responsible for its replication and infectivity. Later, gypsy was isolated and sequenced from the genomes of Drosophila virilis and Drosophila subobscura (Mizrokhi and Mazo 1991; Alberola and De Frutos 1996).

Southern- and dot-blot screenings have shown that the gypsy retrotransposon is widely distributed in the genus Drosophila (Stacey et al., 1986; Alberola et al., 1997; Loreto et al., 1998). However, close inspection of these

Send correspondence to Vera Lúcia S. Valente. Universidade Federal do Rio Grande do Sul, Avenida Bento Gonçalves 9500, Bloco B, Prédio 43323, Caixa Postal 15053, 91501-970 Bairro Agronomia, Porto Alegre, RS, Brazil, Email: vera.gaiesky@ufrgs.br. data revealed that the different hybridization signals using a D. melanogaster gypsy probe do not strictly follow the traditional phylogeny of the genus (hybridization signals being indicative of homology between sequences).

Lambertsson et al. (1989) used restriction-site polymorphism analysis to demonstrate the coexistence of several gypsy subfamilies in the D. melanogaster genome and that the majority of gypsy copies are defective and greatly divergent, while Chalvet et al. (1998) used the same approach and the presence of discrete HindIII and $X b a \mathrm{I}$ restriction sites to discover and characterize an active $D$. melanogaster gypsy subfamily.

The widespread presence of gypsy homologues in Drosophila was initially thought to be because the gypsy retrotransposon was present in the ancestral genome before the main radiation branches separated, with subsequent expansion occurring by vertical transmission (Alberola \& De Frutos 1996). Nevertheless, Southern-blot and phylogenetic studies of gypsy sequences within groups of Drosophila species has pointed to a more complex evolutionary picture, including the possibility of horizontal transfer events (Stacey et al., 1986; De Frutos et al., 1992; Alberola \& De Frutos 1993 ${ }^{\mathrm{a}, \mathrm{b}}$, 1996; Terzian et al., 2000; Vázquez-Manrique et al., 2000). Our recent findings suggest that multiple horizontal transfer events have indeed occurred during the recent evolutionary history of gypsy (Herédia et al., 2004). 
This scenario is supported by the work of Mejlumian et al. (2002), who have reported the existence of DNA sequences putatively encoding full-length and functional env proteins in the genome of Drosophila species closely related to $D$. melanogaster and more distant species such as $D$. virilis and $D$. subobscura. These data strengthen the hypothesis that these sequences are potentially infectious gypsy copies that are able to spread between sexually isolated species.

To gain a more comprehensive insight into the evolutionary history of gypsy in the genus Drosophila, we carried out a broad Southern blot and polymerase chain reaction (PCR) analysis of 42 Drosophila species belonging to different species groups and subgenera (several of which had not hitherto been investigated for the gypsy retrotransposon) together with samples of the Drosophilid Zaprionus indianus which has recently been introduced into South America (Vilela, 1999).

Isofemale lines of all the species studied were established and reared in cornmeal medium (Marques et al., $1966)$ at constant temperature and humidity $\left(17^{\circ} \mathrm{C} \pm 1^{\circ} \mathrm{C}\right.$; $60 \%$ relative humidity). A list of all the species investigated and the number of populations employed is given in Table 1. Approximately 100 adult flies per sample were macerated with liquid nitrogen in a $1.5 \mathrm{~mL}$ microcentrifuge tube and the genomic DNA extracted using the method of Jowett (1986).

Table 1 - List of species and Southern blot and polymerase chain reaction (PCR) results plus the estimated copy number of gypsy retroelements (estimated using BamHI) and the number of fragments larger than $7 \mathrm{~kb}$ (based on BglII), probably representing complete gypsy copies. The banding patterns were compared separately to D. melanogaster, $D$. virilis (both used as controls) and $D$. subobscura restriction maps and classified as being positive or negative for the melanogaster $(\mathrm{M})$, virilis $(\mathrm{V})$ or subobscura $(\mathrm{S})$ expected fragment or having unexpectedly high signal bands $(\mathrm{H})$. Species that did not produce fragments of the expected length (M, V or S) or a high signal band are indicated by an ' $\mathrm{X}$ '. Species with the melanogaster fragment are indicated by ' $\mathrm{M}$ ' and with the subobscura fragment by ' $\mathrm{S}$ '. The abbreviation 'na' indicates that data was not available for this species.

\begin{tabular}{|c|c|c|c|c|c|c|c|c|}
\hline \multirow{2}{*}{$\begin{array}{l}\text { Subgenus, group and species } \\
\text { (number of populations } \\
\text { analyzed) }\end{array}$} & \multicolumn{3}{|c|}{ Southern blot analysis } & \multicolumn{3}{|c|}{$\begin{array}{l}\text { PCR analysis primers (positive }(+) \text { or negative } \\
(-) \text { for the specified primers ) }\end{array}$} & \multicolumn{2}{|c|}{ Gypsy retroelement data } \\
\hline & HindIII & $B g l I I$ & BamHI & $\begin{array}{l}\text { GYP1S/ } \\
\text { GYP1AS }\end{array}$ & $\begin{array}{l}\text { GYP31S/ } \\
\text { GYP3AS }\end{array}$ & $\begin{array}{l}\text { GYP32S/ } \\
\text { GYP3AS2 }\end{array}$ & $\begin{array}{l}\text { Gypsy copy } \\
\text { number }\end{array}$ & $\begin{array}{c}\text { Number of frag- } \\
\text { ments }<7 \mathrm{~kb}\end{array}$ \\
\hline \multicolumn{9}{|l|}{ Drosophila subgenus } \\
\hline \multicolumn{9}{|l|}{ guarani group } \\
\hline D. maculifrons (1) & $\mathrm{X}$ & M & $\mathrm{H}$ & + & - & + & 9 & 4 \\
\hline D. griseolineata (1) & $\mathrm{H}$ & $\mathrm{M}, \mathrm{H}$ & $\mathrm{X}$ & - & - & + & 12 & 4 \\
\hline D. ornatifrons (1) & $\mathrm{X}$ & $\mathrm{H}$ & $\mathrm{X}$ & - & - & + & 6 & 3 \\
\hline \multicolumn{9}{|l|}{ cardini group } \\
\hline D. polymorpha (3) & $\mathrm{X}$ & $\mathrm{X}$ & $\mathrm{X}$ & - & - & + & 16 & 2 \\
\hline D. cardinoides (1) & $\mathrm{X}$ & $\mathrm{X}$ & $\mathrm{X}$ & - & - & - & 12 & 4 \\
\hline D. neocardini (1) & $\mathrm{X}$ & $\mathrm{X}$ & $\mathrm{X}$ & - & - & - & 16 & 3 \\
\hline \multicolumn{9}{|l|}{ immigrans group } \\
\hline D. immigrans (3) & $\mathrm{X}$ & $\mathrm{H}$ & $\mathrm{X}$ & - & - & - & 10 & 1 \\
\hline \multicolumn{9}{|l|}{ pallidipennis group } \\
\hline D. pallidipennis (1) & $\mathrm{X}$ & $\mathrm{H}$ & $\mathrm{H}$ & + & + & + & 15 & 3 \\
\hline \multicolumn{9}{|l|}{ tripuntacta group } \\
\hline D. bandeirantorum (2) & $\mathrm{X}$ & $\mathrm{X}$ & $\mathrm{X}$ & + & + & + & 12 & 1 \\
\hline D. angustibucca (1) & $\mathrm{X}$ & $\mathrm{X}$ & $\mathrm{H}$ & - & - & - & 13 & 4 \\
\hline D. mediopunctata (1) & $\mathrm{X}$ & $\mathrm{H}$ & $\mathrm{X}$ & + & - & + & 10 & 2 \\
\hline D. mediosignata (1) & na & $\mathrm{H}$ & $\mathrm{X}$ & - & - & + & 12 & 2 \\
\hline D. mediopicta (1) & $\mathrm{X}$ & na & $\mathrm{X}$ & + & - & + & 15 & 3 \\
\hline D. mediostriata (1) & M & $\mathrm{X}$ & $\mathrm{X}$ & + & - & + & 12 & 3 \\
\hline \multicolumn{9}{|l|}{ virilis group } \\
\hline D. virilis (1) & Control & Control & Control & Control & Control & Control & na & na \\
\hline \multicolumn{9}{|l|}{ repleta group } \\
\hline D. hydei (1) & $\mathrm{H}$ & $\mathrm{H}$ & $\mathrm{X}$ & + & + & + & 10 & 3 \\
\hline D. zotti (1) & na & na & na & + & + & + & na & na \\
\hline D. mercatorum (3) & $\mathrm{H}$ & $\mathrm{H}$ & $\mathrm{H}$ & - & - & - & 7 & 2 \\
\hline \multicolumn{9}{|l|}{ bromelioides group } \\
\hline D. bromelioides (1) & na & na & na & - & + & - & na & na \\
\hline
\end{tabular}


Table 1 (cont.)

\begin{tabular}{|c|c|c|c|c|c|c|c|c|}
\hline \multirow{2}{*}{$\begin{array}{l}\text { Subgenus, group and species } \\
\text { (number of populations } \\
\text { analyzed) }\end{array}$} & \multicolumn{3}{|c|}{ Southern blot analysis } & \multicolumn{3}{|c|}{$\begin{array}{l}\text { PCR analysis primers (positive }(+) \text { or negative } \\
(-) \text { for the specified primers ) }\end{array}$} & \multicolumn{2}{|c|}{ Gypsy retroelement data } \\
\hline & HindIII & $B g l I I$ & BamHI & $\begin{array}{l}\text { GYP1S/ } \\
\text { GYP1AS }\end{array}$ & $\begin{array}{l}\text { GYP31S/ } \\
\text { GYP3AS }\end{array}$ & $\begin{array}{l}\text { GYP32S/ } \\
\text { GYP3AS2 }\end{array}$ & $\begin{array}{l}\text { Gypsy copy } \\
\text { number }\end{array}$ & $\begin{array}{c}\text { Number of frag- } \\
\text { ments }<7 \mathrm{~kb}\end{array}$ \\
\hline \multicolumn{9}{|l|}{ annulimana group } \\
\hline D. annulimana $(1)$ & na & na & na & + & + & + & na & na \\
\hline \multicolumn{9}{|l|}{ Sophophora subgenus } \\
\hline \multicolumn{9}{|l|}{ willistoni group } \\
\hline D. willistoni (2) & $\mathrm{X}$ & $\mathrm{X}$ & $\mathrm{X}$ & - & - & + & 7 & 1 \\
\hline D. nebulosa (1) & $\mathrm{X}$ & $\mathrm{H}$ & na & - & + & + & na & na \\
\hline D. fumipennis (1) & na & $\mathrm{X}$ & na & - & - & - & na & na \\
\hline D. paulistorum (1) & $\mathrm{X}$ & $\mathrm{X}$ & $\mathrm{X}$ & - & - & + & 6 & 0 \\
\hline D. bocainensis (1) & $\mathrm{X}$ & $\mathrm{X}$ & $\mathrm{X}$ & - & - & - & 8 & 2 \\
\hline D. capricorni (1) & $\mathrm{X}$ & na & na & - & + & - & na & na \\
\hline D. equinoxialis (1) & na & na & na & + & - & - & na & na \\
\hline D. tropicalis (1) & $\mathrm{H}$ & $\mathrm{X}$ & $\mathrm{X}$ & - & - & - & 13 & 4 \\
\hline D. sucinea (1) & $\mathrm{X}$ & $\mathrm{X}$ & na & - & - & - & na & na \\
\hline D. insularis (1) & $\mathrm{X}$ & $\mathrm{X}$ & $\mathrm{X}$ & - & - & - & 10 & 2 \\
\hline \multicolumn{9}{|l|}{ saltans group } \\
\hline D. prosaltans $(1)$ & na & $\mathrm{H}$ & $\mathrm{X}$ & - & + & - & 8 & 2 \\
\hline D. sturtevanti (7) & $\mathrm{X}$ & na & na & + & + & - & na & na \\
\hline \multicolumn{9}{|l|}{ melanogaster group } \\
\hline D. kikkawai (1) & $\mathrm{X}$ & $\mathrm{X}$ & $\mathrm{X}$ & + & + & - & 11 & 3 \\
\hline D. melanogaster (1) & Control & Control & Control & Control & Control & Control & 23 & 6 \\
\hline D. ananassae (1) & $\mathrm{X}$ & $\mathrm{H}$ & $\mathrm{X}$ & - & - & - & 16 & 2 \\
\hline D. malerkotliana (1) & $\mathrm{X}$ & $\mathrm{H}$ & $\mathrm{X}$ & + & + & - & 11 & 2 \\
\hline D. simulans (3) & $\mathrm{M}, \mathrm{H}$ & $\mathrm{X}$ & $\mathrm{X}$ & + & + & + & 4 & 0 \\
\hline \multicolumn{9}{|l|}{ Scaptodrosophila subgenus } \\
\hline D. lebanonensis (1) & $\mathrm{X}$ & $\mathrm{X}$ & $\mathrm{X}$ & - & + & - & 13 & 3 \\
\hline D. galloi (1) & $\mathrm{X}$ & $\mathrm{X}$ & $\mathrm{X}$ & - & - & - & 13 & 3 \\
\hline D. latifasciaeformis (1) & $\mathrm{H}$ & $\mathrm{X}$ & $\mathrm{X}$ & - & - & + & 10 & 1 \\
\hline \multicolumn{9}{|l|}{ Dorsilopha subgenus } \\
\hline D. busckii (2) & $\mathrm{H}, \mathrm{S}$ & $\mathrm{H}$ & $\mathrm{X}$ & + & + & + & 4 & 3 \\
\hline \multicolumn{9}{|l|}{$\begin{array}{l}\text { Zaprionus subgenus } \\
\text { armatus group }\end{array}$} \\
\hline Z. indianus (1) & NA & M & $\mathrm{X}$ & + & + & + & 14 & 2 \\
\hline
\end{tabular}

Southern blotting was carried out using the pGGHS plasmid as the probe, this plasmid containing the complete D. melanogaster gypsy retroelement (Dorsett et al., 1989). Figure 1 shows the molecular structure of the $D$. melanogaster gypsy retrotransposon, highlighting the ORFs, LTRs and the restriction sites for the endonucleases used in our study (BglII, HindIII and BamHI, all from Invitrogen). Figure 1 also shows the restriction polymorphism between the complete elements described in the literature for $D$. virilis and D. subobscura, the maps constructed using the pDRAw 321.0 program (Kjeld Olesen, freeware). The number of copies of the retrotransposon per genome was estimated using $B a m \mathrm{HI}$, for which there are no internal restriction sites in the D. melanogaster gypsy transposon. The BglII endonucleases was used to recognize sequences located in the gypsy LTRs, 7-kb fragments indicating the presence of probable complete gypsy retrotransposons. We cleaved $10 \mu \mathrm{g}$ of each DNA sample with the restriction enzymes cited above according to the manufacturers' instructions. The fragments produced were fractionated on $0.8 \%(\mathrm{w} / \mathrm{v})$ agarose gels, transferred to a Hybond $\mathrm{N}+$ membrane (Amersham Biosciences) and hybridized with the probe according to the Gene Images ${ }^{\circledR}$ kit protocol (Amersham Biosciences). The probe was labeled with a random primer and hybridized at $60{ }^{\circ} \mathrm{C}$ in a solution containing $0.1 \%(\mathrm{w} / \mathrm{v})$ sodium dodecyl sulfate (SDS), $5 \%$ 


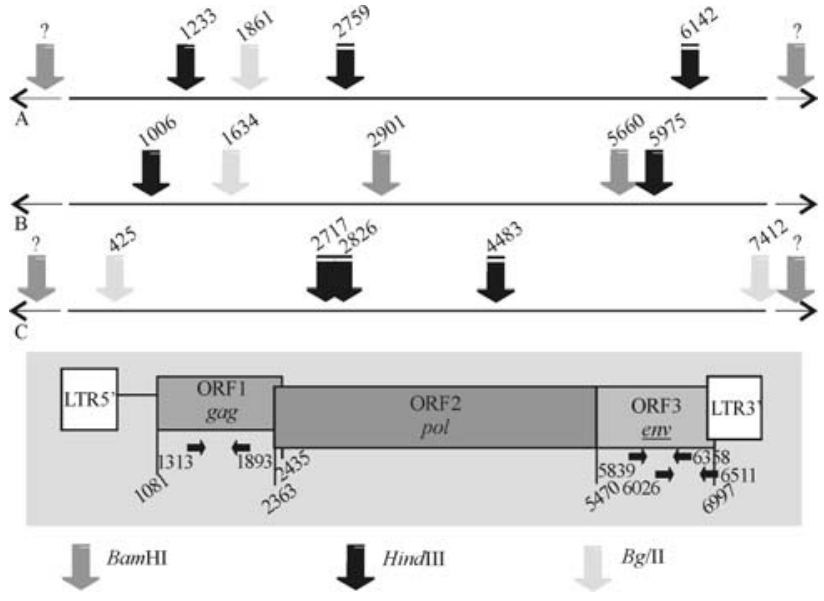

Figure 1 - The molecular structure of the gypsy retrotransposon. The numbers inside the smaller box indicate the nucleotide position of the open reading frame (ORF) limits and the location of the primer alignments. Above the smaller box are the restriction maps for the Drosophila species subobscura (A), virilis (B) and melanogaster (C) with the restriction sites for enzymes used in this work indicated by arrows, with the numbers showing the exact positions of the restriction sites.

$(\mathrm{w} / \mathrm{v})$ dextran sulfate and a blocking liquid (from the kit) diluted 20 times in $5 \mathrm{x}$ saline-sodium citrate (SSC) buffer. The membrane was washed by shaking for $15 \mathrm{~min}$ at $60^{\circ} \mathrm{C}$ in $1 \times \mathrm{SSC}$ and $0.1 \%(\mathrm{w} / \mathrm{v}) \mathrm{SDS}$ and then in $0.5 \mathrm{x} \mathrm{SSC}$ and $0.1 \%(\mathrm{w} / \mathrm{v})$ SDS and the fragments detected using the CPD-Star ${ }^{\circledR}$ kit (Amersham Biosciences). The molecular length of the fragments (in $\mathrm{kb}$ ) detected was determined using a $1 \mathrm{~kb}$ Plus DNA ladder ${ }^{\circledR}$ (GIBCO/BRL) molecular weight marker as a control. The complex banding patterns obtained were compared separately to $D$. melanogaster, $D$. subobscura, and $D$. virilis restriction maps and classified as possessing, or not possessing, the melanogaster expected fragment (M), the subobscura expected fragment (S) or the virilis expected fragment $(\mathrm{V})$, with a further category for those banding fragments with unexpectedly high signal bands (H-bands). Figure 2 shows the banding pattern obtained and illustrates the fragment classification.

For PCR analysis we designed three pairs of degenerate primers based on GenBank (NCBI) gypsy sequences alignments for D. melanogaster (GenBank M12927), D. virilis (GenBank M38438) and D. subobscura (GenBank $\mathrm{X} 72390$ ) and using the $D$. melanogaster sequence as reference, the primers being: GYP1S (sense GAGTTTGCAGG TGGARGCRCC, ORF1 region 1313-1333) and GYP1AS (antisense GCRAACARGCTTCTCTCWATGCTWGC, ORF1 region 1869-1893) coding for a 580-nt fragment; GYP3S1 (sense YCTMGATTTCTTAGGYACWGC, ORF3 region 5839-5859) and GYP3AS1 (antisense GTCYTCGTCGAGKCGCARRAT, ORF3 region 63366358) coding for a 519-nt fragment; and GYP3S2 (sense AAAGGCGAYTTGGTTGACACTCC, ORF3 region 6026-6048) and GYP3AS2 (antisense CARGTGGCTRGG TTGRGTGTG, ORF3 region 6491-6511) coding for a
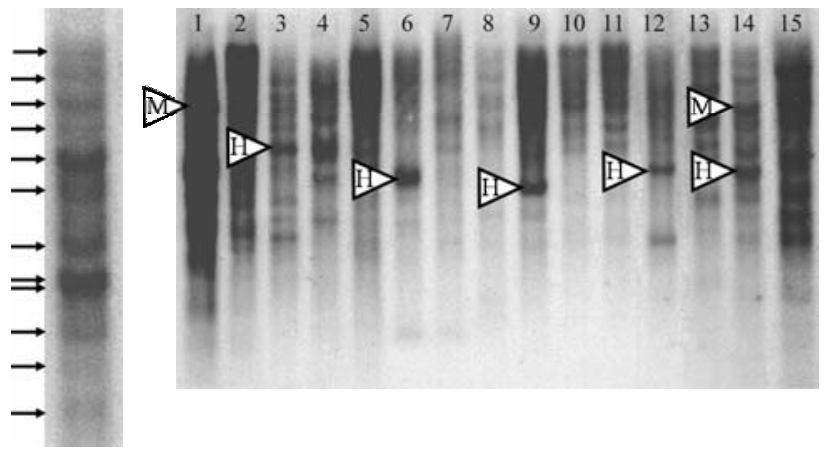

Figure 2 - A) An example of the estimation of the gypsy retrotransposon copy number using the BamHI restriction pattern. Southern blot analysis (12 bands) of Drosophila griseolineata total genomic DNA isolated and digested with BamHI. B) Southern blot analysis of total genomic DNA isolated from different Drosophila species and digested with the $B g l \mathrm{II}$ restriction enzyme. The complete $D$. melanogaster gypsy sequence was used as a probe. Numbers correspond to the following Drosophila species: 1) D. melanogaster - Harwich; 2) D. cardinoides; 3) D. pallidipennis; 4) D. mediopunctata; 5) D. mediostriata; 6) D. nebulosa; 7) D. tropicalis; 8) D. sucinea; 9) D. ananassae; 10) D. lebanonensis; 11) D. galloi; 12) D. malerkotliana; 13) D. polymorpha; 14) D. griseolineata; 15) D. neocardini. Arrows indicate the restriction pattern classification. $\mathrm{M}=$ melanogaster expected fragment; $\mathrm{H}=$ high signal band. Molecular markers are shown in $\mathrm{kb}$. All banding patterns were checked and confirmed using different exposure times.

485-nt fragment. The letters R, W and Y represent degenerate positions in the primers.

The reaction mixture consisted of $50 \mathrm{ng}$ of sample DNA, 1 unit of Taq polymerase (Invitrogen), $50 \mathrm{mM}$ of each nucleotide, 20 pmol of each primer and $1.5 \mathrm{mM}$ of $\mathrm{MgCl}_{2}$ in a volume of $50 \mu \mathrm{L}$. Amplification was for $2 \mathrm{~min}$ at $96{ }^{\circ} \mathrm{C}$ followed by 35 cycles of $15 \mathrm{~s}$ at $96{ }^{\circ} \mathrm{C}, 30 \mathrm{~s}$ at $55^{\circ} \mathrm{C}$ and $90 \mathrm{~s}$ at $72{ }^{\circ} \mathrm{C}$, with a final extension for $5 \mathrm{~min}$ at $72^{\circ} \mathrm{C}$. Products were separated on $1 \%$ agarose gels.

We evaluated the distribution of gypsy-homologous sequences in different Drosophila species and compared the conservation of their restriction sites in relation to those found in D. melanogaster by Southern blot. However, some of the species were difficult to rear in the laboratory and did not provide enough flies to extract DNA for all of the restriction site analyses.

We detected gypsy-homologous sequences in all the species investigated, indicating that this retrotransposon is ubiquitous in this genus. However, the hybridization patterns of the different species were very diverse and characterized by a high number of bands and weak hybridization signals. The bands observed were mostly weak as compared with those of the D. melanogaster control DNA.

As outlined above, the complex banding patterns were classified as the melanogaster expected fragment (M), the subobscura expected fragment (S) or the virilis expected fragment $(\mathrm{V})$, with a further category for those banding fragments with unexpectedly high signal bands (H-bands) probably reflecting the products of a new internal restriction pattern involving more than one restriction site in the gypsy sequence (Table 1, Figure 2b). 
In the majority of the species we investigated, the HindIII and BglII restriction fragments did not correspond to those normally seen in the $D$. melanogaster reference map, indicating that the gypsy restriction sites in the species studied diverged from those of $D$. melanogaster.

Although the gypsy elements in Drosophila mediostriata and D. simulans showed a similar $1.7-\mathrm{kb}$ fragment as D. melanogaster after HindIII digestion, those in Drosophila busckii had fragments of about 3.4 and $1.5 \mathrm{~kb}$, possibly corresponding to those expected for the Drosophila subobscura gypsy element (Figure 1). High signal bands $(\mathrm{H})$ were seen in other Drosophila species (griseolineata, hydei, mercatorum, busckii, simulans, tropicalis and latifasciaeformis), indicating the diversity of restriction sites in the different species.

In the blots in which the genomic DNAs of the species studied were cleaved with BglII endonuclease, the approximately 7-kb gypsy fragment expected for $D$. melanogaster was also observed in D. griseolineata, Drosophila maculifrons and Z. indianus. Unexpectedly high signal bands (H-bands) were found in some Drosophila species (immigrans, mediosignata, hydei, mercatorum, prosaltans, busckii, pallidipennis, mediopunctata, nebulosa, ananassae, malerkotliana, ornatifrons and griseolineata). The fact that the same enzymes did not show homologous H-bands in all species investigated suggests that there are different restriction patterns among the different species (Figure 2b).

The estimated the copy number of gypsy homologous sequences as exemplified in Figure 2a varied from 4 to 16 in the 32 species assessed (Table 1). In most of the species studied the BamHI bands were estimated as being in excess of $7.5 \mathrm{~kb}$ and probably represented complete copies of the gypsy retrotransposon because BamHI does not recognize internal gypsy restriction sites. However, these estimates should nevertheless be regarded as preliminary because our results showed restriction polymorphism in the gypsy sequences of these species.

The divergence and probable activity of the gypsy-homologous sequences at the population level were evaluated for some of the species by studying the HindIII digests of different populations (Table 1). Six of the seven Drosophila species showed no variation in gypsy HindIII banding, the exception being Drosophila sturtevanti.

Of the 42 species examined with the 3 different primer pairs (Table 1) 28 species produced PCR products for at least one pair. The fact that 12 species were negative although the D. melanogaster gypsy probe had produced positive hybridization signals in Southern blotting suggests that nucleotide substitutions may have occurred in the annealing regions of the primers. Some Drosophila species (pallidipennis, bandeirantorum, hydei, zotti, annulimana, simulans and busckii) and Z. indianus showed the expected PCR fragments with the three pairs of primers employed and the PCR bands were equivalent to those obtained for the controls (D. melanogaster and $D$. virilis).

Our results confirm and extend the finding that the gypsy retrotransposon is widely distributed within the genus Drosophila and that there are heterogeneous banding patterns, restriction polymorphism, and both complete and deleted copies of this transposon in the investigated genomes (Alberola and De Frutos, 1993 ${ }^{\mathrm{b}}$; Alberola et al., 1997; De Frutos et al., 1992; Loreto et al., 1998; Stacey et al., 1986). Our previous study on the same drosophilid species has shown that different gypsy subfamilies can coexist in the same genome and that gypsy exhibits a complex evolutionary pattern in which multiple invasion of the host genome can occur (Herédia et al., 2004). Taking together, these aspects may explain the Southern blot banding patterns that we obtained in our present study. We propose that the divergence in restriction sites reflects the deterioration of ancient gypsy sequences, whereas the conserved restriction pattern in distant species indicates the introduction of new gypsy sequences as a result of recent invasion of the host genome by the gypsy retrotransposon.

Our BglII Southern blot results show that although $D$. griseolineata, D. maculifrons and $Z$. indianus are phylogenetically very distant from $D$. melanogaster, they appear to have complete copies of the gypsy retrotransposon with homologous sequences in which the BglII cleavage pattern is maintained. We also found that the typical $D$. melanogaster restriction pattern was neither observed in the remaining species of the melanogaster group nor in other closely related species such as those belonging to the subgenus Sophophora (except for D. simulans). Inconsistencies of this type were previously pointed out by Stacey et al. (1986). Furthermore, we found that the HindIII melanogaster expected fragment (M) was only detected in $D$. simulans and $D$. mediostriata, the latter species being only very distantly related to $D$. melanogaster. The same case was observed for the subobscura expected fragment (S) in D. busckii. Interestingly, horizontal transmission events have been described between D. busckii and D. subobscura and between $D$. simulans (a sibling species of $D$. melanogaster) and Z. Indianus (Herédia et al., 2004). The PCR results also demonstrated the high homology among gypsy sequences of these species.

It is important to point out that in our study the variability of gypsy sequences at the inter-specific level did not occur at the inter-population level where we observed genomic stability in the gypsy profiles. These findings confirm the results described by Sassi et al. (2005) for different populations of Drosophila willistoni.

Both Southern blot and PCR were capable of detecting the complex evolutionary patterns, confirmed by the phylogenetic analysis (see Herédia et al., 2004) and appear to be a good tool for the preliminary screenings of transposable elements in different Drosophila genomes. Southern blot methodology is particularly useful because it can be 
used to assess the indirect variability of the complete sequence of the transposable element while other methods can only assess just a small part of the sequence, resulting in restricted conclusions about the presence, divergence and evolutionary aspects of these elements.

\section{Acknowledgments}

This work was supported by grants from Brazilian agencies CNPq, PROPESQ-UFRGS, FINEP, and FAPERGS. We thank Dr. Daniela Cristina De Toni and Luciano Basso da Silva for samples of the flies and Dr. Dale Dorsett who kindly provided the pGGHS plasmid. We are also grateful to Dr. Pierre Capy for critical comments on the manuscript.

\section{References}

Alberola TM and De Frutos R (1993a) Gypsy homologous sequences in Drosophila subobscura (gypsy DS). J Mol Evol 36:127-135.

Alberola TM and De Frutos R (1993b) Distribution of gypsy sequences in Drosophila species of the obscura subgroup. Hereditas 118:131-137.

Alberola TM and De Frutos R (1996) Molecular structure of a gypsy element of Drosophila subobscura (gypsy DS) constituting a degenerate form of insect retroviruses. Nucleic Acids Res 24:914-923.

Alberola TM, Bori L and De Frutos R (1997) Structural analysis of Drosophila subobscura gypsy elements (gypsy Ds). Genetica 100:39-48.

Bayev Jr. AA, Lyubomirskaya NV, Dzhumagaliev EB, Ananiev EV, Amiantova IG and Ilyin YV (1984) Structural organization of transposable element mdg4 from Drosophila melanogaster and a nucleotide sequence of its long terminal repeats. Nucleic Acids Res 12:3707-3723.

Chalvet F, Di Franco C, Terrinoni A, Pelisson A, Junakovic N and Bucheton A (1998) Potentially active copies of the gypsy retroelement are confined to the $\mathrm{Y}$ chromosome of some strains of Drosophila melanogaster possibly as the result of the female-specific effect of the flamenco gene. J Molec Evol 46:437-441.

De Frutos R, Peterson KR and Kidwell MG (1992) Distribution of Drosophila melanogaster transposable element sequences in species of the obscura group. Chromosoma 101:293-300.

Dorsett D, Viglianti GA, Rutledge BJ and Meselson M (1989) Alteration of $h s p 82$ gene expression by the gypsy transposon and supressor genes in Drosophila melanogaster. Genes Dev 3:454-468.

Georgiev GP, Ilyin YV, Chmeliauskaite VG, Ryskov AP, Kramerov DA, Skryabin KG, Krayev AS, Lukanidin EM and Grigoryan MS (1981) Mobile dispersed genetic elements and other middle repetitive DNA sequences in the genomes of Drosophila and mouse: Transcription and biological significance. Cold Spring Harbor Symp Quant Biol 45:641654.
Herédia F, Loreto ELS and Valente VLS (2004) Complex evolution of gypsy in Drosophilid species. Mol Biol Evol 21:1831-1842.

Jowett T (1986) Drosophila: A Practical Approach. 2nd edition. Oxford University Press, Washington DC, $416 \mathrm{pp}$.

Kim A, Terzian C, Santamaria P, Pelisson A, Prud'homme N and Bucheton A (1994) Retroviruses in invertebrates: The gypsy retrotransposon is apparently an infectious retrovirus of Drosophila melanogaster. Proc Natl Acad Sci USA 91:1285-1289.

Lambertsson A, Andersson S and Johansson T (1989) Cloning and characterization of variable-sized gypsy mobile elements in Drosophila melanogaster. Plasmid 22:22-31.

Lerat E. and Capy P (1999) Retrotransposons and retroviruses: Analysis of the envelope gene. Mol Biol Evol 6:1198-1207.

Loreto ELS, Da Silva LB, Zaha A and Valente VLS (1998) Distribution of transposable elements in neotropical species of Drosophila. Genetica 101:153-165.

Marin I and Lloréns C (2000) Ty31Gypsy retrotransposons: Description of new Arabidopsis thaliana elements and evolutionary perspectives derived from comparative genomic data. Mol Biol Evol 17:1040-1049.

Marques EK, Napp M, Winge H and Cordeiro AR (1966) A corn meal, soybean flour, wheat germ medium for Drosophila. D I S 41:187.

Mejlumian L, Pelisson A, Bucheton A and Terzian C (2002) Comparative and functional studies of Drosophila species invasion by the gypsy endogenous retrovirus. Genetics 160:201-209.

Miller K, Lynch C, Martin J, Herniou E and Tristem M (1999) Identification of multiple gypsy LTR-retrotransposon lineages in vertebrate genomes. J Mol Evol 49:358-366.

Mizrokhi LJ and Mazo AM (1991) Cloning and analysis of the mobile element gypsy from $D$. virilis. Nucleic Acids Res 19:913-916.

Pelisson A, Teysset L, Chalvet F, Kim A, Prud'homme N, Terzian $\mathrm{C}$ and Bucheton A (1997) About the origin of retroviruses and the co-evolution of the gypsy retrovirus with the Drosophila flamenco host gene. Genetica 100:29-37.

Sassi AK, Heredia F, Loreto ELS, Valente VLS and Rohde C. Transposable elements $P$ and gypsy in natural populations of Drosophila willistoni. Genet Mol Biol 28:734-739.

Stacey SN, Lansman RA, Brock HW and Grigliatti TA (1986) Distribution and conservation of mobile elements in the genus Drosophila. Mol Biol Evol 3:522-534.

Terzian C, Ferraz C, Demaille J and Bucheton A (2000) Evolution of the gypsy endogenous retrovirus in the Drosophila melanogaster subgroup. Mol Biol Evol 17:908-914.

Vázquez-Manrique RP, Hernández M, Martínez-Sebastián MJ and De Frutos R (2000) Evolution of gypsy endogenous retrovirus in the Drosophila obscura species group. Mol Biol Evol 17:1185-1193.

Vilela CR (1999) Is Zaprionus indianus Gupta, 1970 (Diptera, Drosophilidae) currently colonizing the Neotropical region? D I S 82:37-39.

Xiong Y and Eickbush TH (1990) Origin \& evolution of retroelements based upon their reverse transcriptase sequences. EMBO J 9:3353-3362.

Associate Editor: Louis Bernard Klaczko 